\title{
LA FICCIÓN EXPLORATIVA EN LA FILMOGRAFÍA DE CHRISTOPHER NOLAN
}

\author{
Angélica García Manso \\ fjtovar@unex.es \\ UNIVERSIDAD DE EXTREMADURA
}

Recibido: 4 de julio de 2018

Aceptado: 20 de noviembre de 2018

DOI: http://dx.doi.org/10.15366/didacticas2018.19.006

\section{Resumen}

El estudio aborda el filme Interstellar (2014), del director británico Christopher Nolan, desde la perspectiva narratológica de la "ficción explorativa" aplicada al Séptimo Arte. Para ello se consideran desde el punto de vista del género tres hitos en la filmografía del cineasta: se trata de Memento (2000), Origen (2010) y la citada Interstellar, filme este último en el que la optatividad del relato implica al espectador. Ello se confirma en el contenido que expresan los "taglines" de los carteles.

Palabras clave: Cine; Ciencia Ficción; Análisis Textual; Estética del Film; Educación Mediática.

\begin{abstract}
Our study deals with the film Interstellar (2014), by British director Christopher Nolan, from the narratological perspective of "explorative fiction" applied to the Seventh Art. For this purpose, three filmmaking milestones are considered from the point of view of the genre: Memento (2000), Origen (2010) and the aforementioned Interstellar, a film in which the optional nature of the story involves the spectator. This idea is confirmed by the content of the taglines on the posters.
\end{abstract}

Keywords: Cinema; Science Fiction: Textual Analysis: Film Aesthetics; Media Education. 


\section{1.- INTRODUCCIÓN: INTERSTELLAR DESDE LA PERSPECTIVA DEL GÉNERO DE LA CIENCIA FICCIÓN LITERARIA Y CINEMATOGRÁFICA}

En el mes febrero de 2016 se confirmaba empíricamente, a través de un experimento del observatorio astronómico estadounidense "LIGO" situado en el Instituto Tecnológico de California, la teoría de Albert Einstein acerca de las ondas gravitacionales, lo cual ha supuesto un revulsivo para las Ciencias Físicas más actuales. Con la película Interstellar (2014), dirigida por el cineasta británico Christopher Nolan, el cine se había anticipado algo más de un año a la confirmación de la hipótesis de tales ondas, relacionadas con un aserto vinculado a la conocida Teoría de la Relatividad. Con motivo del estreno del filme, la crítica cinematográfica hizo particular hincapié en la prolija documentación científica de la que hacía gala la película, convertida ésta en buena medida y a pesar de sus detractores (que encuentran el soporte doctrinal de fondo incoherente), en un referente divulgativo sobre la posibilidad de viajar en el tiempo; y ello, al margen del género literario y cinematográfico específico sobre el tema en el marco de la Ciencia Ficción.

Esto implica que el filme de Nolan posee un valor pedagógico cualificado para las disciplinas científicas, pero no sólo para las ciencias matemáticas y físicas. Y es que se trata de un relato de ciencia ficción en el que se plantea que la Humanidad ha de abandonar un planeta contaminado e improductivo, para lo cual tiene que buscar otros lugares para sobrevivir, nuevos enclaves en los que asentarse. Entre tanto, la Tierra necesita ingenieros agrónomos, geólogos y meteorólogos, cuyos respectivos ámbitos de estudio están presentes en el largometraje -sobre todo en su primera parte, en la introducción que contextualiza la narración-, aunque el foco fundamental se encuentra, ciertamente, en los conocimientos astrofísicos, como son, por ejemplo, los relativos a las paradojas temporales. Así, tales paradojas se ofrecen en el filme primordialmente en un sentido: las distintas velocidades a las que parece transcurrir el tiempo y, sus consecuencias: la recuperación por parte del personaje principal de unos hijos que, en el momento en que se produce el reencuentro, pueden tener más edad que el propio padre protagonista. Las peripecias de la expedición interestelar ocupan gran parte del metraje, hasta que los pioneros quedan reducidos a una pareja de personajes, que optan por separarse in extremis para que el protagonista pueda cumplir su promesa de regresar a la Tierra, aunque su retorno se produzca a un planeta que, de alguna manera, ha dejado de ser el suyo. Uno de los hitos de tales peripecias está representado por el desplazamiento a través de un agujero negro cuyo comportamiento físico se explica en sus líneas más generales con esquemas didácticos $a d$ hoc, si bien lo que se muestra y sucede en el citado fenómeno es totalmente imaginario.

En apariencia, salvo por la oportunidad del filme (según se confirmaría con el descubrimiento de las ondas gravitacionales en meses posteriores) y salvo el enfoque científico y la calidad de la producción, podría considerarse una película representativa del género de Ciencia Ficción "de escala humana" según la fórmula revitalizada en el último lustro por superproducciones o blockbusters como Gravity (2013), dirigida por 
Alfonso Cuarón, o The Martian (2015), de Ridley Scott, y plenamente inmerso en la llamada "ficción prospectiva" o "especulativa" en torno a las posibilidades hipotéticas del devenir del ser humano en la Tierra.

No obstante, Interstellar cuenta con un aspecto adicional que convierte la película en peculiar dentro del género: la forma mediante la que aborda el relato Christopher Nolan, su director. Nos referimos a una poética fílmica en la que, aparte de la originalidad que se desprende del tratamiento de cada tema concreto (incluso cuando cada uno de tales temas responde a una fórmula cerrada, como también sucede en relación con el superhéroe Batman en varias de las películas que Nolan ha dirigido hasta el momento y con anterioridad a Interstellar), prima el enfoque narrativo conocido como "ficción explorativa" o de opción hipertextual. Se trata, empero, de una expresión que no tiene vínculo ni con el género de la Ciencia Ficción ni con el tema de los viajes de prospección cosmológica. Todo lo contrario: aplicado a un filme como Interstellar y al conjunto de la producción de Nolan, la noción de "ficción explorativa" implica la transformación de una finalidad didáctica basada en argumentos de tipo científico y tecnológico hacia una lectura diferente, de índole más humanística, que se cimenta en las consecuencias sociales y culturales del relato (Casas, 2013).

\section{2.- LA NOCIÓN NARRATOLÓGICA DE "FICCIÓN EXPLORATIVA"}

Desde una perspectiva narratológica, la expresión "ficción explorativa" se emplea para indicar que un relato está construido con un enfoque hipertextual, es decir, en el que se ofrecen una serie de lecturas en abanico que obligan, en apariencia, a la participación del receptor a la hora de optar por una línea del relato u otra. El término "hipertexto", que hunde sus raíces en las teorías de Gérard Genette (Genette, 1989), ha cobrado una enorme relevancia desde el apogeo de las nuevas tecnologías hace un cuarto de siglo (Cuevas, 2005). En efecto, si bien un hipertexto se define como una forma de lectura no lineal sino abierta, en la que tienen cabida otros formatos distintos al propio del texto (como sonidos, imágenes, vídeos), además de otros textos e información en general a los que se llega mediante enlaces, también es cierto que poseen carácter hipertextual lecturas que no son digitales, pero que transcienden el texto desde el momento en que el lector accede a éstas de una manera opcional, son agregativas y suelen identificar a protagonista y espectador mediante la atribución de vivencias compartidas.

La hipertextualidad que se descubre en El Quijote es a este respecto fuertemente representativa (González García, 2009). Así, tras el regreso de Don Quijote a su lugar al final de la primera parte de la novela, Cervantes se halla redactando una nueva salida en el momento en que aparece publicado un texto espurio, firmado por Avellaneda, en el que se relatan nuevas aventuras de Alonso Quijano. Una vez que se publique la segunda parte propiamente cervantina, el lector podrá “optar" por una versión u otra, que se convierten en lecturas hipertextuales mutuas desde el momento en el que Cervantes incluye la espuria versión de Avellaneda en su obra. De igual forma, se puede considerar que, si se llevara 
a cabo una edición de la novela del ingenioso hidalgo sin los agregados de las novelas e historias insertas, la comprensión de las aventuras no sufriría menoscabo, toda vez que los insertos poseen un carácter hipertextual y por ello ofrecen la posibilidad de ser antologizables, pues en su concepción se presentan como agregados. En fin, la identificación del personaje con los héroes de las novelas de caballería anteriores es de tal calibre que éstas funcionan, ciertamente, como hipertextos del propio texto cervantino, dado que el personaje se atribuye a sí mismo las características heroicas de los caballeros andantes (Moreno, 2007).

La "ficción explorativa" en el contexto de la hipertextualidad responde básicamente a la idea de que un texto - - , en su caso, un filme, como sucede en Nolan- supera sus límites básicos de alto por ancho y una dirección de lectura o visionado lineales para desarrollar unas posibilidades expresivas más amplias, que implican la participación activa del lector o espectador en calidad de restaurador de un puzzle. Eso sí, al ser el volumen de un libro o un filme un entorno cerrado, el director posee todas las claves del relato, pero deja su resolución en manos del espectador, a partir de las pistas que le va ofreciendo en un abanico de opciones aparentemente idénticas pero que se excluyen entre sí, así como a partir de tramas paralelas, enigmas, trueques espacio-temporales, etcétera, tal como pondremos de manifiesto a propósito de los filmes de Christopher Nolan objeto de análisis (García, 2012).

De esta manera, es posible trasladar la clave didáctica de Interstellar desde sus referentes científicos a claves de lectura como las descritas que, además, incumben un ámbito social y humanístico, más aún si se considera su condición fílmica, es decir, la posibilidad de evocar dentro del filme la misma Historia del Cine, según podrá comprobarse en los siguientes epígrafes.

\section{3.- LA “FICCIÓN EXPLORATIVA" EN LA FILMOGRAFÍA DE NOLAN}

Del conjunto de la filmografía de Christopher Nolan, los filmes Memento (2000) y Origen (Inception, 2010), además de Interstellar, constituyen ejemplos significativos de "fícción explorativa". La implicación del espectador, sin embargo, se hace en cada una de estas tres películas de forma diferente, como corresponde a los géneros fílmicos en que es posible inscribir cada una de ellas: Memento como cine negro, Origen dentro del marco de la "ciber-realidad" y, finalmente, Interstellar en calidad de "space opera" prospectiva en el sentido que acabamos de definir. Cosa diferente sucede con otras películas del director, caso de la última película estrenada, con Dunkirk (2017), dado que, en este filme, los hechos responden a una base histórica, dentro del género bélico en el marco de la II Guerra Mundial, de forma que la "ficción explorativa" aparece tamizada por un evidente contexto extranarrativo (Memento, Origen e Interstellar constituyen ficciones absolutas). De igual forma, en lo que se refiere al tratamiento que hace Nolan de la figura de Batman inevitablemente ha de insertar su propuesta en el carácter extradiegético del superhéroe, 
tanto en versiones fílmicas previas como en otras manifestaciones editoriales e iconográficas.

Así, en lo que se refiere a Memento, la trama gira en torno a un agente de seguros que padece problemas con la memoria inmediata y es incapaz de almacenar recuerdos en el lapso temporal que se da entre vigilia y vigilia, es decir, durante el sueño, de forma que cada día ha de reconstruir su historia reciente (Alonso, 2011). Ello tiene dos implicaciones inmediatas desde la Historia del Cine: de un lado se evoca el filme Perdición (Double Indemnity, 1944), clásico del Séptimo Arte dirigido por Billy Wilder sobre un título del escritor de novela negra Raymond Chandler que está protagonizado también por un agente de seguros que reconstruye de memoria su complicidad en un asesinato; y, de otro lado, convierte a su personaje, en virtud de su amnesia, en el candidato ideal para cometer un "crimen perfecto", por citar un filme de Alfred Hitchcock, tal y como se plantea también en cierta medida en la película Recuerda (Spellbound, 1945), del propio Hitchcock.

De ahí que al espectador con formación cinéfila se le ofrezca no sólo el contexto genérico de la película, sino dos posibles relatos acerca del personaje dentro de dicha clave negra: sea éste víctima o asesino (Pardo, 2007). Es, por consiguiente, el espectador el que "explora" ambas posibilidades dentro de una ficción cuyo núcleo narrativo, sin embargo, no va a girar en torno a los recuerdos de un crimen sino a la cronología de los hechos que se reconstruyen. A este último respecto, se van a presentar dos opciones: el crimen ha sido cometido en el pasado y el personaje busca cada día comprender con nuevos datos qué sucedió y poder vengarse, responder o, al menos, saber; o, en segundo lugar, se prepara al personaje amnésico para la comisión de un crimen, tras hacerle creer que fue su negligencia la que está detrás de la enfermedad cerebral que padece. En otras palabras, se trata, al cabo, de una nueva bifurcación de carácter "explorativo" a la que se somete al espectador.

En lo que concierne a la narración propiamente dicha, la hipotética causa de la amnesia tiene que ver originariamente con la investigación del agente de seguros en torno a un cliente sin memoria, cuya esposa ha fallecido por un error accidental o, de ahí la investigación, fruto de una premeditación criminal (Rainho, 2008). De alguna manera, es el propio personaje el que, a la vez que el espectador, ha de elegir entre dos posible relatos. Pero lo realmente llamativo (algo que incluso podría parecer forzado en el tratamiento de un tema de carácter inusual) procede de la duplicación de amnésicos, aspecto éste que provoca un intenso extrañamiento, hasta el punto de hacer pensar al espectador que no se trata de dos personajes, sino de un único personaje desdoblado (Sánchez, 2008).

Según se puede comprobar, el carácter poliédrico del relato exige del receptor una atención continuada para terminar convirtiéndose él mismo, a la vez que el personaje, en una especie de "tercer hombre", que reconstruya cada apunte, cada fotografía de formato Polaroid, cada tatuaje en el cuerpo (Williams, 2003); y ello con opciones acumulativas además de simultáneas: víctima o asesino, crimen pasado o futuro, error o premeditación, un único protagonista o dos, entre otras, cuya complicación se vuelve laberíntica si se 
hacen permutaciones entre dichas opciones (Muñoz, 2009). E incluso, si a la manera del texto de Rayuela, de Julio Cortázar, se plantea la posibilidad de que sea el propio espectador el que ordene las secuencias de distintas formas para llegar a una idea aproximada del relato, haciendo él mismo de director de montaje (que puede coincidir o no con el montaje "lineal" que se ofrece en la versión en DVD editada en el año 2011).

A este respecto, el momento clave del filme, el cual se produce aproximadamente en el minuto ochenta y tres, abre una nueva opción, la posibilidad de que el personaje se encuentre en una institución psiquiátrica, como sucede en el clásico El Gabinete del Doctor Caligari (Das Kabinett des Dr. Caligari, 1920), de Robert Wiene, o en Recuerda, de Hitchcock, antes citado. Es más, el relato de Jonathan Nolan, hermano del director, del que parte Memento y que subyace en su trama -cuyo título es Memento Mori (publicado en 2001)-, hace hincapié precisamente en la reclusión del protagonista en un hospital psiquiátrico (Nolan, 2001; Caldevilla, 2012). De esta manera, se resalta y hace más evidente el carácter hipertextual del filme ante el abanico de posibilidades que se ofrecen de continuo en el marco de la "ficción explorativa".

La propuesta de Memento se basa en la memoria. La de Origen, por su parte, tiene como leitmotiv central el sueño. En Origen las figura del investigador de seguros se traslada a la de un "extractor de sueños", es decir, hacia la de una figura profesional ficticia, inexistente en la actualidad y en la realidad como profesión: la del experto capaz de introducirse, mediante la administración de drogas, en el subconsciente de otra persona para así robarle claves informáticas y bancarias, proyectos empresariales, patentes, etcétera, en un ámbito puramente imaginario, heredado en cierta medida de filmes como, entre otros títulos, Matrix (1999), dirigido por los hermanos Wachowski. El tiempo cronológico al que se atiende en la película se muestra como el presente, aunque no se sabe a ciencia cierta si responde a un presente real u onírico: se trata del lapso que abarca un viaje de avión en un vuelo de diez horas, si bien son varios los personajes implicados en las tramas y subtramas asociadas al vuelo. En el decurso de la narración, el protagonista se plantea crear una "inception", es decir, una nueva idea en el subconsciente de otro para conseguir escapar del conflicto que constituye la trama, pero ha de hacerlo en sueños dentro de sueños, a la clásica manera del relato dentro del relato; o, trasladado al ámbito económico, de empresas tapadera que se solapan con otras empresas tapadera; en uno y otro caso como forma de difuminar la identidad y los intereses reales que ocultan el motor de dicha trama.

El espectador se enfrenta, por consiguiente, a una doble elección de género, que oscila entre lo virtual (si se percibe el filme como un videojuego) y lo real (la película como crónica de un viaje); o, también, entre un personaje que tiene una profesión inexistente a fecha de hoy y aquél que desarrolla durante un vuelo una intriga para llevar a cabo un asalto económico de tipo empresarial. Es decir, entre la "ciber-realidad" y la realidad. Por lo demás, al igual que en Memento se pasaba de la memoria al tiempo, en Origen se pasa del sueño a la realidad virtual, objeto central del relato. Y es que la ficción 
se diluye en sueños que son como secciones de un juego de realidad virtual (González, 2010).

Así, el espectador del filme ha de ser consciente tanto del nivel de juego (o sueño) que se le plantea como de la congruencia de que los personajes se anulen o no en función de la profundidad de la escala de "no-vigilia" a la que se asiste (Dempsey, 2010). Es decir, como en un relato dentro de un relato que se inscribe en otro relato, si un personaje queda anulado en el nivel más profundo, deja de poder ser partícipe en relatos de niveles más próximos e incluso desaparecer como relatador y convertir la lectura de los sucesos en incongruente. No en vano, el nivel de juego/sueño más profundo es conocido como "limbo", del que hay que retornar hacia los demás niveles para poder seguir existiendo (Hill-Parks, 2011).

Ciertamente en el filme se ofrecen pistas sobre el nivel de realidad en el que se mueven los personajes, pistas que sirven no sólo a cada uno de ellos, sino también al espectador. Éste tiene que percibir activamente tales pistas para continuar con su "exploración" en la ficción: se trata, entre otros motivos, de una peonza que, en el plano más real, detiene su movimiento, un girar que es infinito en los demás planos. Despertar y dormir se convierten en pliegues espacio-temporales sobre la realidad y el juego virtual. Al final, ha de prevalecer una perspectiva única: la del personaje principal, aunque ésta se vacíe en su condición de personaje de película. Y la "inception" a la que se asiste resulta ser, al cabo, la que Nolan ha depositado con su película en cada espectador. De ahí la importancia de que éste se interne en la ficción. En efecto, el personaje del "extractor" transmite continuamente la sensación de que alguien se le anticipa en cada paso que da. Exactamente igual que sucede con la relación director/espectador del filme: el primero controla todo el relato, pero lo presenta al espectador como una suma de posibilidades abiertas, de opciones, de enigmas que ha de ir resolviendo durante el visionado para poder disfrutar del filme, a pesar de que, en todo momento, alguien le guía (Heuring, 2010).

Por consiguiente, el carácter de "ficción explorativa" de Origen se basa en la atribución del espectador como partícipe de la confusión entre realidad y virtualidad propias de una película. De hecho, uno de los aspectos que más tinta ha hecho correr a la hora de interpretar el filme se refiere a su final abierto, en el que se observa la peonza giratoria y un fundido que impide saber si el protagonista culminaba su investigación en el plano real (dentro del filme, obviamente) o virtual, es decir, entre su realidad o su sueño.

\section{4.- LA LECTURA COMO FICCIÓN EXPLORATIVA DE INTERSTELLAR}

Desde la perspectiva de su progresión narrativa, Interstellar se presenta como una película más lineal que lo que se ofrece en Memento y Origen, acaso debido a que su tema central sea, precisamente, el tiempo (no ya la memoria o el sueño, como en los títulos citados). Además, uno de los axiomas físicos más determinantes afirma que el tiempo únicamente 
avanza, y lo hace hacia un futuro que se vuelve continuamente presente para cada personaje; de ahí que la trama de la película se haga coincidir con dicha percepción lineal del tiempo. No obstante, la cuestión radica en que cada uno de los personajes asume la percepción del tiempo a un ritmo diferente, de acuerdo, además, con la Teoría General de la Relatividad de Albert Einstein, que hace depender del observador la percepción del movimiento, de la velocidad y del propio tiempo.

La coexistencia de tiempos distintos provoca las diferentes tensiones del relato, sobre todo cuando al planeta Tierra parece estar "acabándosele el tiempo" en un futuro cercano (que parece bastante semejante al presente en temas como la destrucción ecológica y el cambio climático, además de la sobreexplotación de los recursos) y con tal final se anuncia también el de la Humanidad. Existen señales al respecto, que se ofrecen en diversos planos (un dron perdido, una tormenta seca, un enigma magnético), que aportan las pautas de las disparidades entre la Tierra actual y la que se muestra en la cinta: un planeta desmilitarizado, climatológicamente devastado y sometido en apariencia a tensiones geológicas de carácter catastrófico. De esta manera, el espectador penetra en el filme a través de contrastes. Pero su implicación es también de otro tipo: debe considerar y reconsiderar continuamente el género que le ofrece el filme a partir de la proximidad de lo que ve con su propia experiencia en el mundo contemporáneo y, a la vez, a partir de sus conocimientos como espectador de cine.

Así, el filme se abre como un western familiar, en el que el padre muestra a sus hijos cómo cazar (aunque el objeto de la caza sea un dron y la persecución se haga en una furgoneta desvencijada). Por lo demás, el terreno en el que viven padece dos amenazas: una primera de índole apocalíptica por los huracanes de polvo que asolan los cultivos y parece propia del género fílmico conocido como "de catástrofes"; y una segunda más misteriosa que se da en la casa de la granja familiar, repleta de enigmas: enseres y libros descolocados, desplazamientos magnéticos, claves de comunicación antiguas mediante código morse, etcétera, a la manera de, por citar un único ejemplo, el filme Poltergeist (1982), de Tobe Hooper. Pero el mensaje oculto conduce a una base secreta de la NASA, mediante la que se evoca el clásico Encuentros en la Tercera Fase (Close Encounters of the Third Kind, 1978), dirigido por Steven Spielberg. Y así sucesivamente, pues, sin afán de ser exhaustivos, por descontado no faltan en Insterstellar referencias y alusiones a películas como El planeta de los simios (Planet of the Apes, 1968), de Franklin Schaffner, cuando se aterriza en un entorno acuático, ni al clásico 2001 (2001, A Space Odyssey, 1968), dirigida por Stanley Kubrick, en todo lo que se refiere a la percepción conceptual de las nuevas dimensiones.

En otro orden de cosas, la película presenta continuamente a los personajes en la tesitura de la elección: marchar a la misión interestelar con el riesgo de no regresar que ésta comporta o vivir como granjero apegado a un terruño amenazado; enviar expediciones para encontrar planetas habitables o salvaguardar la genética humana en un viaje sin tripulación; optar por visitar dos planetas (entre tres posibles candidatos a albergar vida) o por cuál de los dos restantes una vez que la primera elección ha resultado 
fallida; rescatar al compañero accidentado a contrarreloj o abandonarlo para no poner en riesgo los planes debido a las distorsiones del tiempo que se producen en el lugar en el que se encuentra; etcétera. Es verdad que se trata de opciones demasiado básicas tal como aparecen reflejadas en el filme, pero, a su vez, responden a pulsiones perfectamente asumibles para el espectador al margen de los conocimientos científicos que éste posea.

En este contexto de suma de posibles géneros y de la continua necesidad de elegir a la que se obliga a los personajes, el final del largometraje resulta extraño en virtud del cúmulo de encrucijadas indicadas: de un lado, el tiempo vence y derrota a padre e hija en su lucha por converger en una edad lógica y natural; de otro, la trama se resuelve de forma sentimental, pero no en un sentido peyorativo, sino en el sentido, inspirado en Dostoievski y trasladado al Séptimo Arte por directores de la talla de Robert Bresson, de que todos los acontecimientos desembocan en el encuentro entre dos personas (como forma, asimismo, de superar la viudedad del protagonista, en una línea afín al cine de Ciencia Ficción, según reflejan filmes como Solaris -Solyaris, 1972-, dirigido por Andrei Tarkovski e inspirado en un relato del escritor Stanislav Lem).

En definitiva, la película muestra una baza final en buena medida inesperada para el espectador, pues una trama que se apoya en una relación paterno-filial deriva hacia la de una relación de pareja. También el desenlace responde a una lógica que superpone el cálculo racional al afectivo: la exploración espacial impone la renuncia a las obligaciones y sentimientos familiares. Finalmente, al romperse la lógica natural de que los padres tengan más edad que los hijos y que fallezcan antes que éstos, la resolución del filme hace hincapié en la extrañeza que provoca esta circunstancia en el protagonista y que es causa de su alejamiento del planeta. Sea como fuere, se trata de un aspecto temático no tanto científico cuanto de orígenes clásicos y de índole mitológica, en la idea de un "cosmos" que deriva en "caos" al quedar roto el orden natural de las edades. Esta circunstancia permite releer en una clave diferente la confusión de tiempos que se da, según hemos analizado, en Memento y Origen: en estos filmes los personajes principales aparecen como seres desplazados de la realidad, de la cotidianidad -por así decir-, sea por la amnesia que sufren o por la capacidad que han adquirido para penetrar en los sueños ajenos; seres, por consiguiente, del "caos", cuyo retorno al "orden" se deja en manos del espectador.

En Interstellar, no obstante, no sucede así debido precisamente a que el filme gira en torno al tiempo, si bien es cierto que el espectador sigue presentándose como parte imprescindible del relato, y ello incluso desde las premisas científicas de la cinta. Y es que, de acuerdo con asertos propios de la Física Cuántica, los fenómenos existen desde el momento en que son observables y observados. De esta manera, la película surge de su visionado, de la misma forma que, si fuera posible el viaje a través de un agujero negro, éste lo sería una vez descubierto el agujero, no antes. Al seguirse en la trama de Nolan las peripecias del personaje principal, la película aparece ordenada; si se abandona a éste, surgiría, como posibilidad que se ofrece como trasfondo al espectador, un caos que haría imposible el visionado coherente del filme o el filme en sí. 


\section{5.- CONCLUSIÓN: TAGLINES Y CARACTERIZACIÓN HIPERTEXTUAL}

Desde una perspectiva propiamente temática, en el análisis de Interstellar la aparición de conceptos como los de mecánica cuántica, ondas gravitacionales o agujeros de gusano, permite su abordaje como ejemplo para una Didáctica de las Ciencias, por estar planteados, además, sin excesos terminológicos ni teorías complejas para los no iniciados. Pero si se desciende a la construcción de la película, su lectura didáctica se abre a perspectivas diferentes, que incumben al ámbito social, humanístico y cultural.

En efecto, de un lado, los problemas demográficos y las soluciones para la supervivencia implican una reflexión sobre el ser humano, la explotación del planeta, el final de la guerra, el legado generacional. De otro lado, la implicación del espectador responde a claves narratológicas que operan en el conjunto de la filmografía del director Christopher Nolan y en la Historia del Cine, con títulos señeros y relevantes a este respecto.

Un ejemplo sintomático de la propuesta prospectiva que ofrece Nolan puede descubrirse en la publicidad de los filmes, más en concreto en los carteles de los mismos. Así, desde una perspectiva exclusivamente textual, se descubren en los pósteres oficiales de las producturas citas - expresiones denominadas "taglines"- que describen una primera impresión del largometraje para el espectador con anterioridad a su visionado. Lo llamativo en el caso de Nolan radica en cómo dichos taglines ofrecen pautas hipertextuales según las hemos definido con anterioridad, e implican de forma directa al espectador en la ficción explorativa de sus filmes.

En este orden de cosas, si se recorren los taglines de Memento, Origen e Interstellar se descubre cómo se busca la connivencia del espectador en la ambigüedad aparente de las citas en tanto no se conocen las películas. Así se percebe el tagline "Some memories are best forgotten", donde la contradicción entre recuerdo y olvido se hace presente como decisión individual del personaje de Memento, con toda la anfibología que ello provoca. En "Your mind in the scene of the crime", tagline principal de Origen, se efectúa una sutil distinción entre el lugar físico y el mental, dejando en manos del espectador la elección del sitio en que se encuentra. Finalmente, en el caso de Interstellar, existen diferentes taglines, en función de que se trate de "teasers" (pósteres inscritos en la campaña de prelanzamiento) o carteles oficiales. Entre los primeros, se impone el esfuerzo por mantener la idea de linealidad hacia adelante en "Go further"; mientras que en "The End of Earth will not be the end of us" $\mathrm{y}$ en "Mankind was born on Earth; it was never mean to die here" domina el mantenimiento del orden cronológico de nacimiento y muerte y el cósmico acerca del futuro posterior al planeta Tierra, en calidad de sucesos que, en apariencia, podrían contradecirse con lo que el espectador verá en el relato fílmico, pero que, a su vez, lo hacen cómplice necesario durante el visionado. 


\section{BIBLIOGRAFÍA}

ALONSO CANO, O. (2011): "La experiencia truncada: estudio de la amnesia anterógrada como representación del sujeto empirista en Memento (2000)". En Journal of Medicine and Movies/ Revista de Medicina y Cine, 7, pp. 85-93.

CALDEVILLA, D. (2012): "El relato corto en el cine: Memento". En Icono14. Revista de comunicación y tecnologías emergentes, 10, pp. 168-195 <https://dx.doi.org/10.7195/ri14.v10i2.414 >.

CASAS DELGADO, I. (2013): "In Nolan we trust: La obsesión onírica y psicológica que ha conquistado Hollywood". En Frame, 9, pp. 85-102.

CUEVAS ÁllaREZ, E. (2005): "Christopher Nolan visto desde Gérard Genette: análisis narratológico de Memento". En Zer, 18, pp. 183-198.

DEMPSEY, M. (s. d.): "Inception Explained", disponible en <http://inceptionexplained.com/ > [09/04/2017].

GARCÍA FORNET, I. (2012): "Los laberintos de la realidad: el cine de Cristopher Nolan". En El coloquio de los perros. Revista de Literatura, 31, disponible en <http://www.elcoloquiodelosperros.net/numero31/anda31ig.html > [09/04/2017].

GENETTE, G. (1989): Palimpsestos. La literatura en segundo grado. Madrid: Taurus.

GONZÁLEZ, C. (2010): “Inception”, Revista LetraMedia, disponible en $<$ http://www.letramedia.cl/?p=884 > [11/04/2016].

GONZÁLEZ GARCÍA, M. (2009): Educar con el Quijote: Del canon al hipertexto. Murcia: Universidad de Murcia.

HEURING, D. (2010): "Wally Pfister, ASC and Christopher Nolan offer AC an inside view of the sci-fi thriller Inception". En The American Society of Cinematographers, 91, disponible

en <https://www.theasc.com/ac_magazine/July2010/Inception/page1.php [13/04/2017].

HILL-PARKS, E. E. (2011): "Identity Construction and Ambiguity in Christopher Nolan's Films". En Wide Screen, 3, pp. 1-18.

MORENO PINAUD, J. (2007): "El hipertexto Quijote: el silencio de Cervantes. Apropiaciones quijotescas en Latinoamérica". En Espéculo. Revista de Estudios Literarios, 34 , disponible en <https://pendientedemigracion.ucm.es/info/especulo/numero34/hiperqui.html> [15/04/2016].

MUÑOZ CORCUERA, A. (2009): "El caso de Memento: una memoria nietzscheana en el cine postmoderno”. En Bajo Palabra. Revista de Filosofía, 4, pp. 181-190.

NOLAN, C. (2001): Memento \& Following. London: Faber \& Faber. 
PARDO GARCÍA, P. J. (2007): "El relato antipolicial en la literatura y el cine: Memento, de Christopher Nolan”. En Martín Escribà, Alex y Sánchez Zapatero, Javier (eds.), Informe confidencial: la figura del detective en el cine negro. Valladolid: Difácil, pp. 249-264.

RAINHO VEGAS, S. I. (2008): “Olhar e Memória na Percepçâo Cinematográfica”. En Principios, 24, pp. 31-44.

SÁNCHEZ LÓPEZ, R. (2008): “Christopher Nolan y el memento mágico". En AACADigital. Revista de la Asociación Aragonesa de Críticos de Arte, 3, disponible en <http://www.aacadigital.com/contenido.php?idarticulo=89> [17/04/2017].

WILLIAMS, G. C. (2003): "Factualizing the Tattoo: Actualizing Personal History Through Memory in Christopher Nolan’s Memento". En Post Script, 23, pp. 27-36. 